\title{
Combination of metformin and sorafenib suppresses proliferation and induces autophagy of hepatocellular carcinoma via targeting the mTOR pathway
}

\author{
SUNBIN LING ${ }^{1,2 *}$, LEI SONG ${ }^{3 *}$, NING FAN ${ }^{2,4^{*}}$, TINGTING FENG ${ }^{5}$, LU LIU $^{4}, \mathrm{XU}_{\text {YANG }}{ }^{4}$, MINGJIE WANG $^{4}$, \\ YANLING LI $^{2}$, YU TIAN ${ }^{2}$, FENG ZHAO ${ }^{2}$, YING LIU ${ }^{4}$, QIHONG HUANG ${ }^{2}$, \\ ZHAOYUAN HOU ${ }^{2}$, FEI XU ${ }^{4}$, LEI SHI ${ }^{4}$ and $\mathrm{YAN} \mathrm{LI}^{2,4}$ \\ ${ }^{1}$ Division of Hepatobiliary and Pancreatic Surgery, Department of Surgery, The First Affiliated Hospital, \\ Zhejiang University School of Medicine, Hangzhou, Zhejiang 310003; ${ }^{2}$ Institute of Cancer Stem Cell, \\ Dalian Medical University, Dalian, Liaoning 116044; ${ }^{3}$ The Second Affiliated Hospital of Dalian Medical University, \\ Dalian, Liaoning 116023; ${ }^{4}$ College of Basic Medical Sciences, Dalian Medical University, Dalian, Liaoning 116044; \\ ${ }^{5}$ Department of Intergrative Medicine, Zhejiang Cancer Hospital, Hangzhou, Zhejiang 310022, P.R. China
}

Received October 11, 2016; Accepted December 2, 2016

DOI: 10.3892/ijo.2016.3799

\begin{abstract}
The multi-kinase inhibitor sorafenib is the only drug for which randomized control trials have shown improved patient survival in advanced hepatocellular carcinoma (HCC). However, life expectancy is extended in these cases by only a few months. The anti-type II diabetes agent metformin was used in this study in an effort to find a more efficient approach to HCC treatment. Sorafenib effectively reversed the activation status of mTORC2 induced by metformin and enhanced the suppression of the mTORC1 and MAPK pathway by metformin in HCC cells, which may be responsible for reduced proliferation upon combined treatment. The metformin and sorafenib combination led to increased impaired proliferation and tumor inhibition of $\mathrm{HCC}$ in vitro and in vivo compared to single agent, which was partially bridged by disrupting the mTORC1/mTORC2 feedback loop. Metformin and sorafenib cooperated to promote apoptosis and autophagy in HCC cells. Pharmacological inhibition of autophagy sensitized HCC cells to metformin and sorefenib-induced apoptotic cell death. Therefore, the anti-autophagy treatment should be considered in metformin and sorafenib-based treatments in HCC cells.
\end{abstract}

Correspondence to: Professor Yan Li, College of Basic Medical Sciences, Dalian Medical University, Dalian, Liaoning 116044, P.R. China

E-mail:1y316@126.com

Dr Lei Shi, Institute of Cancer Stem Cell, Dalian Medical University, 9 West Section Lvshun South Road, Dalian, Liaoning 116044, P.R. China

E-mail: powerleishi@126.com

*Contributed equally

Key words: hepatocellular carcinoma, metformin, sorafenib, mTOR, autophagy

\section{Introduction}

Liver cancer is one of the most common cancers and the third major cause of cancer-related mortality worldwide $(1,2)$. As a major histological subtype, hepatocellular carcinoma (HCC), account for 70 to $80 \%$ of primary liver cancers (3). Despite improvements in clinical treatments, such as surgical resection, liver transplantation and interventional therapy, HCC prognoses remain very poor (1).

Conventional chemotherapies for liver cancer are generally ineffective and the multi-kinase inhibitor sorafenib is the only drug for which randomized control trials have shown an improved survival in advanced HCC (4). Sorafenib inhibits tumor growth through inducing tumor cell apoptosis by suppressing the kinase activity of Raf, an enzyme of the mitogen-activated protein kinase (MAPK) signaling pathway. In addition, sorafenib inhibits VEGF receptor (VEGFR) and platelet-derived growth factor receptor- $\beta$ (PDGF- $\beta$ ) signaling to block tumor angiogenesis (5). However, sorafenib is proved to merely extend the life expectancy of patients with HCC by a few months $(4,6)$ because of the heterogeneity of HCC. Therefore, sorafenib is insufficient to suppress HCC for both primary and secondary drug resistance.

Metformin, a first-line oral anti-type II diabetes agent used worldwide, suppresses tumorigenesis, according to recent epidemic and laboratory studies $(7,8)$. Various explanations for the efficacy of metformin have been proposed, such as the activation of AMPK and the inhibition of insulin-like growth factor signaling and the mammalian target of rapamycin (mTOR) pathway (9). In patients with type II diabetes mellitus, metformin reduced HCC risk and seemed to suppress HCC development (10). In our previous studies, we explored the anti-proliferative effect of metformin in intrahepatic cholangiocarcinoma (ICC) cell lines (11). Metformin may enhance the chemosensitivity of ICC to sorafenib by targeting the AMPK/mTOR complex 1 pathway and the MAPK pathway. In addition, metformin reversed multi-drug 
resistance (MDR) in the $\mathrm{HCC} \mathrm{BEL} / \mathrm{FU}$ cell line by targeting mTOR/HIF-1 $\alpha / \mathrm{p}-\mathrm{gp} / \mathrm{MRP} 1$ (12).

Agent combination based chemotherapy is common used for cancer patients. To develop a novel approach to benefit sorafenib based HCC treatment, we designed this study to evaluate the therapeutic effects and the underlying molecular mechanisms of a combined sorafenib and metformin treatment in a series of pre-clinical studies.

\section{Materials and methods}

Reagents. 1,1-Dimethylbiguanide hydrochloride (metformin, \#D150959-5G), chloroquine (CQ, \#C6628) and 3-methyladenine (3MA, \#M9281) was purchased from Sigma-Aldrich (St.Louis, MO, USA); sorafenib (C21H16ClF3N4O3C7H8O3S, CAS 475207-59-1) was purchased from Selleck Chemicals (Houston, TX, USA); and the cell counting kit-8 (CCK-8, KGA317), the Annexin V-FITC apoptosis detection kit (KGA108), the terminal deoxynucleotidyltransferase-mediated deoxyuridine triphosphate (dUTP) nick-end labeling (TUNEL) assay kit (KGA707), the cell cycle detection kit (KGA512) and the ROS detection kit (KGT010) were purchased from KeyGen Biotech (Nanjing, China). The Histostain ${ }^{\mathrm{TM}}$-Plus kits (IgG/Bio, $\mathrm{S}-\mathrm{A} / \mathrm{HRP}, \mathrm{DAB})$ were purchased from Zhongshan Golden Bridge Co., Ltd. (Beijing, China).

Cell culture. The HCC cell lines Bel-7402 and HepG2 were purchased from the Type Culture Collection of the Chinese Academy of Sciences (Shanghai, China). The cell lines were cultured in RPMI-1640 supplemented with $10 \%$ fetal bovine serum (FBS) (both from Gibco, Carlsbad, CA, USA) and $100 \mu \mathrm{g} / \mathrm{ml}$ each of penicillin and streptomycin (Invitrogen, Carlsbad, CA, USA) in $5 \% \mathrm{CO}_{2}$ at $37^{\circ} \mathrm{C}$.

Antibodies. The following antibodies were used in western blot analysis: $\beta$-actin (sc-47778, diluted 1:1,000) was from Santa Cruz Biotechnology, Inc. (Santa Cruz, CA, USA). AKT (ab126811, diluted 1:1,000) and phosphorylated AKT (phospho-Ser473, ab66138, diluted 1:1,000) were from Abcam (Cambridge, MA, USA). Caspase-3 (AP7563C, diluted 1:1,000), cleaved caspase-3 (AJ1131b, diluted 1:1,000), CDK4 (AP7520b, diluted 1:1,000) and cyclin D1 (AP2612c, diluted 1:1,000) were from Abgent (San Diego, CA, USA). AMPK $\alpha$ (\#2532, diluted 1:1,000) and phosphorylated AMPK $\alpha$ (phospho-Thr172, \#2535, diluted 1:1,000), mTOR (\#2983, diluted 1:1,000), phosphorylated mTOR (phospho-Ser2448, \#5536, diluted 1:1,000), phosphorylated mTOR (phospho-Ser2481, \#2974, diluted 1:1,000), phosphorylated Raptor (phospho-Ser792, \#2083, diluted 1:1,000), phosphorylated p70 S6 kinase (phospho-Thr389, \#9234, diluted 1:1,000), phosphorylated 4E-BP1 (phospho-Thr37/46, \#2855, diluted 1:1,000), PARP (\#9532, diluted 1:1,000), cleaved PARP (\#5626, diluted 1:1,000), ERK (\#4696, diluted 1:2,000), phosphorylated ERK (phospho-Thr202/Tyr204,\#4370, diluted 1:2,000), Ki-67 (\#9449, diluted 1:1,000), LC3-I/II (\#12741, diluted 1:1,000) and p62 (\#8025, diluted 1:1,000) were from Cell Signaling Technology, Inc. (Danvers, MA, USA). Goat anti-rabbit and goat anti-mouse IgG peroxidase-conjugated secondary antibodies (31460 and 31430, both diluted 1:10,000) were from Thermo-Pierce (Rockford, IL, USA). The following antibodies used in the IHC assays were as described above: phosphorylated mTOR (phospho-Ser2448, diluted 1:200), phosphorylated mTOR (phospho-Ser2481, diluted 1:200), phosphorylated AKT (phospho-Ser473, diluted 1:200), phosphorylated ERK (phospho-Thr202/Tyr204, diluted 1:200), cleaved caspase-3 (diluted 1:200), and Ki-67 (diluted 1:200).

Cell viability assay. Cell viability was determined using the CCK-8 assay according to the manufacturer's instructions. Cells $\left(5 \times 10^{3}\right)$ were seeded into a well of a 96-well plate and cultured in $100 \mu \mathrm{l}$ of RPMI-1640 supplemented with $10 \% \mathrm{FBS}$, $100 \mu \mathrm{g} / \mathrm{ml}$ penicillin and $100 \mu \mathrm{g} / \mathrm{ml}$ streptomycin. After $24 \mathrm{~h}$, the agents $(10 \mathrm{mmol} / 1 \mathrm{metformin}$ and/or $5 \mu \mathrm{mol} / \mathrm{l}$ sorafenib) was added to the culture medium. After the cells were incubated at $37^{\circ} \mathrm{C}$ for different times $(24,48$ or $72 \mathrm{~h})$, the medium was changed for $100 \mu \mathrm{l}$ of RPMI-1640 and $10 \mu \mathrm{l}$ of CCK-8 reagent. The cells were incubated for $2 \mathrm{~h}$ at $37^{\circ} \mathrm{C}$. Finally, the optical density was measured using an EnSpire ${ }^{\mathrm{TM}} 2300$ Multilabel Reader (Perkin-Elmer, Waltham, MA, USA) at $450 \mathrm{~nm}$. Five replicates were prepared for each condition. The mean values were calculated and growth curves were drawn.

Clonogenic assay. The inhibitory effect of metformin and sorafenib on HCC cell proliferation was also determined by clonogenic assay. Logarithmic-phase HCC cells were trypsinized and collected, and the resuspended cells were seeded into 6 -well plates in triplicates at a density of 500 cells/well in $2 \mathrm{ml}$ of medium containing $10 \%$ FBS. After a $24 \mathrm{~h}$ incubation, the cultures were replaced with fresh medium containing $2 \%$ FBS and $5 \mathrm{mmol} / 1 \mathrm{metformin}, 2.5 \mu \mathrm{mol} / 1$ sorafenib or their combination and grown for 10 days. The cell clones were stained with a solution containing $1 \%$ crystal violet and $25 \%$ methanol for $2 \mathrm{~min}$. The excess dye was removed by gently rinsing with tap water for $15 \mathrm{~min}$. The average surface of the clones was determined by Image Pro Plus 6.0 software.

Western blot analysis. Cells after different treatments or tumor tissues from xenografts were harvested and lysed in RIPA buffer (KGP702) supplemented with $1 \mathrm{mM}$ phenylmethylsulfonyl fluoride (PMSF; KGP610) and $1 \mathrm{mM}$ phosphatase inhibitor cocktail (KGP602; all from KeyGen Biotech). The mixture was centrifuged at $12,000 \mathrm{x}$ g for $20 \mathrm{~min}$ and the supernatant was collected. The protein concentration was determined using the BCA assay kit (KGPBCA) and each sample contained $30 \mu \mathrm{g}$ protein per $10 \mu \mathrm{l}$. The protein samples were mixed with loading buffer (KGP101) and the proteins were separated using 6,8 or $10 \%$ sodium dodecyl sulfate-polyacrylamide gel electrophoresis (SDS-PAGE) followed by transfer to polyvinylidenedifluoride (PVDF) membranes (Bio-Rad Laboratories, Hercules, CA, USA). After soaking in blocking buffer for $2 \mathrm{~h}$, the blots were incubated with the primary antibody with gentle agitation overnight at $4^{\circ} \mathrm{C}$ and were subsequently incubated at $37^{\circ} \mathrm{C}$ for $1 \mathrm{~h}$ with the HRP-conjugated secondary antibody. The bands were visualized by chemiluminescence, imaged using a ChemiDoc XRS and analyzed using Image Lab (both from Bio-Rad).

Cell cycle, apoptosis and ROS evaluation. To evaluate the effects of metformin on cell cycle arrest, induction of apoptosis and intracellular ROS, the cells were examined using the 
cell cycle detection kit, the Annexin V-FITC apoptosis detection kit and the ROS detection kit, respectively, according to the manufacturer's protocols. Bel-7402 and HepG2 cells were seeded into 6 -well plates $\left(5 \times 10^{4}\right.$ and $1 \times 10^{5}$ cells/dish for analysis of cell cycle arrest and apoptosis, respectively) and incubated for $24 \mathrm{~h}$. For cell cycle analysis, after treatment with agents for $48 \mathrm{~h}$, a total of $1 \times 10^{6}$ cells was pelleted by centrifugation and washed twice with PBS. Then, the cell pellets were resuspended in $500 \mu \mathrm{l}$ of ice-cold $70 \%$ ethanol and incubated at $4{ }^{\circ} \mathrm{C}$ overnight. The fixed cells were centrifuged and the pellets were washed with PBS. After incubation with $100 \mu \mathrm{l}$ RNase A $(10 \mu \mathrm{g} / \mathrm{ml})$ for $30 \mathrm{~min}$ at $37^{\circ} \mathrm{C}$ in the dark, the cells were resuspended in $400 \mu \mathrm{l}$ propidium iodide (PI) $(50 \mu \mathrm{g} / \mathrm{ml})$ and placed at $4^{\circ} \mathrm{C}$ in the dark for $30 \mathrm{~min}$. The stained cells were analyzed using an Accuri C6 flow cytometer (Accuri Cytometers Inc., Ann Arbor, MI, USA).

For the apoptosis analysis, the cells were trypsinized, washed with cold PBS and suspended in PBS. Then, the cells were stained using the Annexin V-FITC reaction reagent $(5 \mu \mathrm{l}$ of Annexin V-FITC, $5 \mu \mathrm{l}$ of PI) at $37^{\circ} \mathrm{C}$ for $30 \mathrm{~min}$ in the dark. The stained cells were analyzed using an Accuri C6 flow cytometer (Accuri Cytometers Inc.).

For the detection of intracellular ROS, an oxidation-sensitive fluorescent probe (DCFH-DA) was used. After treatment with agents for $24 \mathrm{~h}$, a total of $1 \times 10^{6}$ cells was trypsinized and pelleted by centrifugation and washed twice with PBS. Then, the cell pellets were resuspended in $1 \mathrm{ml} \mathrm{RPMI-1640}$ (serum-free) with $10 \mu \mathrm{m} / 1$ DCFH-DA and incubated for $20 \mathrm{~min}$ at $37^{\circ} \mathrm{C}$. The positive control was treated with Rosup according to the manufacturer's protocol (data not shown). The stained cells were analyzed using an Accuri C6 flow cytometer (Accuri Cytometers Inc.). The FL1-A received the fluorescence induced by DCF. For each sample, 20,000 events were collected.

Xenograft model analysis. To investigate the anti-proliferative effect of metformin and sorafenib in combination on HCC cells in vivo, a nude mouse model bearing HCC cell xenografts was established. Five-week-old male athymic nude mice were obtained from the Animal Facility of Dalian Medical University. The mice were maintained under pathogen-free conditions and were provided with sterilized food and water. First, $5 \times 10^{6}$ Bel-7402 cells were injected subcutaneously into the right flank near the hind leg of each nude mouse. When the mice bore palpable tumors (the tumor volume was $\sim 100 \mathrm{~mm}^{3}$ ), they were randomly divided into control [100 $\mu 1$ normal saline (NS) by intraperitoneal injection plus $100 \mu 1$ 1\% dimethyl sulfoxide (DMSO)] and $0.5 \%$ carboxymethyl cellulose [(CMC)-Na sterile water), metformin $(200 \mathrm{mg} / \mathrm{kg} /$ day by intraperitoneal injection plus $100 \mu 11 \%$ DMSO and $0.5 \%$ CMC-Na sterile water)], sorafenib $(30 \mu \mathrm{g} / \mathrm{kg} /$ day by intragastric administration plus $100 \mu \mathrm{NS}$ by intraperitoneal injection) and combination (metformin, $200 \mathrm{mg} / \mathrm{kg} /$ day by intraperitoneal injection plus sorafenib $30 \mu \mathrm{g} / \mathrm{kg} /$ day by intragastric administration) groups ( $\mathrm{n}=6$ animals/group). The treatments were performed for 4 weeks, 5 times/week. The tumor volume was detected every week and was calculated by the following formula: volume $=1 / 2\left(\right.$ length $\mathrm{x}$ width $\left.{ }^{2}\right)$. After 4 weeks, the mice were euthanized and the tumors were isolated.
Immunohistochemical staining. The tumors isolated from the mice were paraffin-embedded and cut into $10 \mu \mathrm{m}$ sections in a microtome cryostat (HM 500 OM; Carl Zeiss, Jena, Germany). Immunohistochemical staining was conducted according to the manufacturer's protocols for the Histostain ${ }^{\mathrm{TM}}$-Plus kits. Primary antibodies (as described in the antibodies section) were incubated at $4^{\circ} \mathrm{C}$ overnight. Images were captured with a light microscope (Axiolab; Carl Zeiss) and 5 images/sample were prepared. The Image-Pro Plus 4.5 software was used to analyze the staining data.

TUNEL assay. In situ detection of apoptotic cells in the tumors isolated from the mice was performed by TUNEL assay. The tumors were paraffin embedded and cut into $10 \mu \mathrm{m}$ sections in a microtome cryostat (HM 500 OM; Carl Zeiss). The TUNEL assay was conducted according to the manufacturer's protocols. 3,3-diaminobenzidine (DAB) was used as the substrate for the peroxidase. The images were captured with a light microscope (Axiolab; Carl Zeiss) and 5 images/sample were prepared. Image-Pro Plus 4.5 software was used to analyze the staining data.

Autophagyanalysis by transmission electronmicroscopy. $\mathrm{HCC}$ cells were harvested by trypsinization and fixed by immersion in $2.5 \%$ glutaraldehyde in $0.1 \mathrm{ml}$ phosphate buffer ( $\mathrm{pH} 7.4$ ). The cells were then post-fixed in $1 \%$ osmium tetroxide, dehydrated in a graded series of ethanol and embedded in epoxy resin. The cells were sliced into $1 \mu \mathrm{m}$ sections and stained with $0.2 \%$ lead citrate and $2 \%$ uranyl acetate. Representative areas were chosen for ultra-thin sections to view with a Tecnai Spirit electron microscope.

Statistical analysis. SPSS 13.0 statistical software was used for the statistical analysis. The values are presented as the mean \pm SD. Statistical analyses were performed using Student's t-test. The analysis of multiple groups was performed with ANOVA with an appropriate post-hoc test.

\section{Results}

Combined treatment of metformin with sorafenib induces impaired proliferation as well as cell cycle arrest in HCC. The effect of a combination treatment of metformin and sorafenib on HCC proliferation was investigated in Bel-7402 and HepG2 cells using CCK-8 and clonogenic assays. The CCK-8 assay revealed a much stronger inhibitory effect of the combination than any single drug treatment for 3 days (Fig. 1A and B). A comparable defect was detected in single cell colony formation (Fig. 1C and D). Over a 10-day treatment, although metformin and sorafenib suppressed single cell colony progression, the combination almost eliminated colony formation. Next, we performed cell cycle analysis. A significant increase in the number of cells arrested in G0/G1 phase was observed in Bel-7402 and HepG2 cells with a combined treatment of metformin and sorafenib compared to the single drug treatment (Fig. 1E and F). Consequently, cyclin D1 and CDK4, the key regulators for $\mathrm{G} 0 / \mathrm{G} 1$ to $\mathrm{S}$ phase transition, were further reduced in Bel-7402 and HepG2 cells (Fig. 1G and H) by the combined treatment when compared to the any single treatment. Remarkably, $10 \mathrm{mmol} / \mathrm{l}$ metformin and $5 \mu \mathrm{mol} / \mathrm{l}$ 

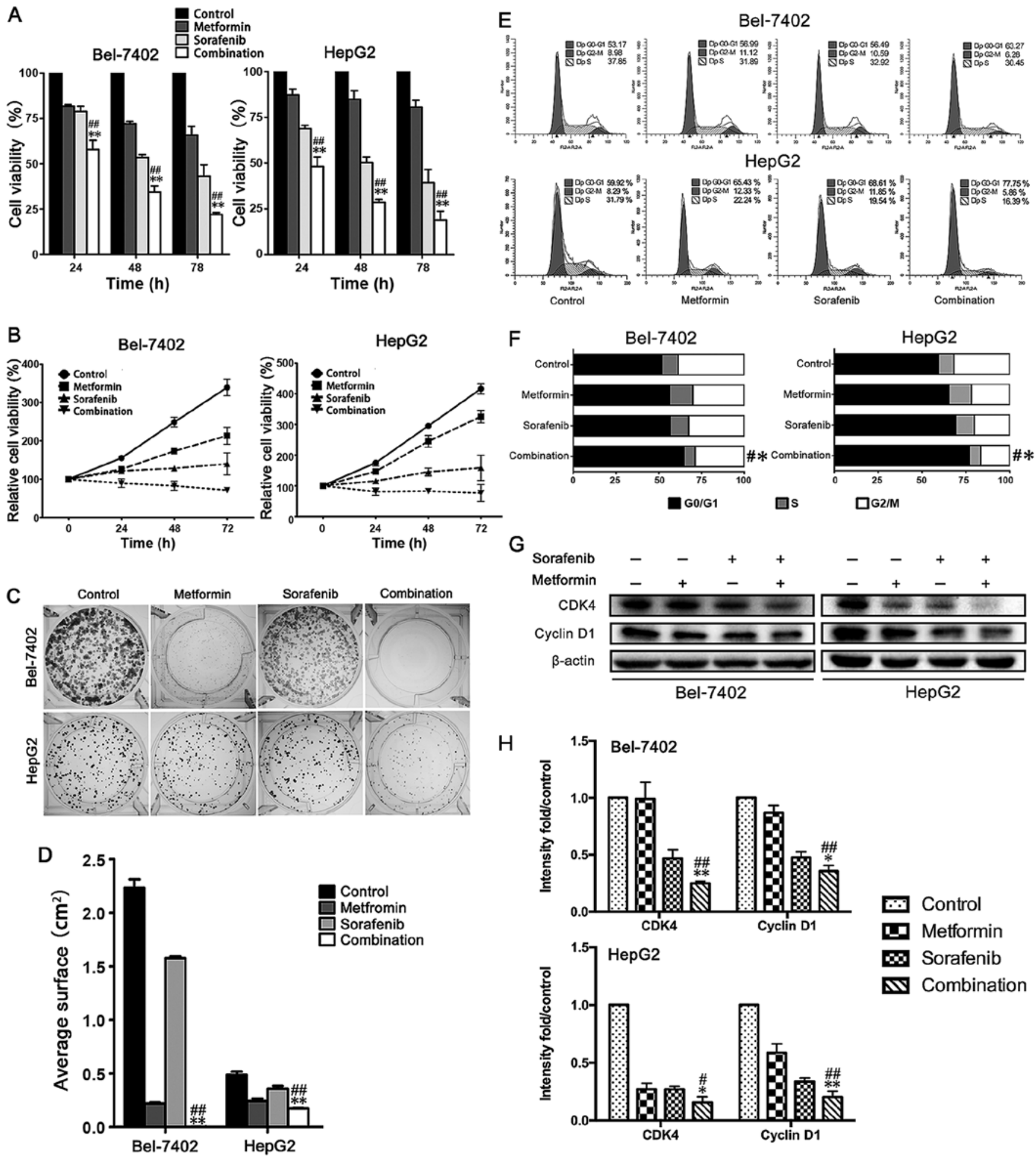

Figure 1. Combination treatment of metformin and sorafenib has more potent antiproliferative activity than single drug treatment in HCC cells. (A) After treatment with $10 \mathrm{mmol} / 1 \mathrm{metformin}$ and $5 \mu \mathrm{mol} / 1$ sorafenib in combination or single treatments for 24,48 or $72 \mathrm{~h}$, the CCK-8 assay was used to determine cell viability. The experiments were repeated 3 times independently and the bars represent the means \pm SD. (B) The growth curves exhibit the growth inhibition of different groups. (C and D) HCC cells were grown in 6-well plates (500 cells/well) in triplicates. After $24 \mathrm{~h}$, the cultures were replaced with fresh medium containing $2 \% \mathrm{FBS}$ and $5 \mathrm{mmol} / 1 \mathrm{metformin}, 2.5 \mu \mathrm{mol} / 1$ sorafenib or their combination. After a 10 day incubation, the colonies were stained with $1 \%$ crystal violet and the average surface of clones was determined by Image Pro Plus software. The bars represent the means \pm SD from 3 independent experiments (E and F) After $48 \mathrm{~h}$ of treatment with $10 \mathrm{mmol} / 1$ metformin, $5 \mu \mathrm{mol} / 1$ sorafenib or their combination, Bel-7402 cells and HepG2 cells were examined using PI staining and the cell cycle distribution was measured by flow cytometric analysis. ( $\mathrm{G}$ and $\mathrm{H}$ ) Cyclin $\mathrm{D} 1$ and $\mathrm{CDK} 4$ were monitored using western blot analysis. Combination vs. metformin ${ }^{~} \mathrm{P}<0.05$ and ${ }^{\# \#} \mathrm{P}<0.01$; combination vs. sorafenib ${ }^{*} \mathrm{P}<0.05$ and ${ }^{* *} \mathrm{P}<0.01$.

sorafenib were used for the CCK- 8 assay and $5 \mathrm{mmol} / \mathrm{l}$ metformin and $2.5 \mu \mathrm{mol} / 1$ sorafenib were used for the clono- genic assay which are described in the figure legends. We had used the same drug concentration of CCK-8 assay in clono- 

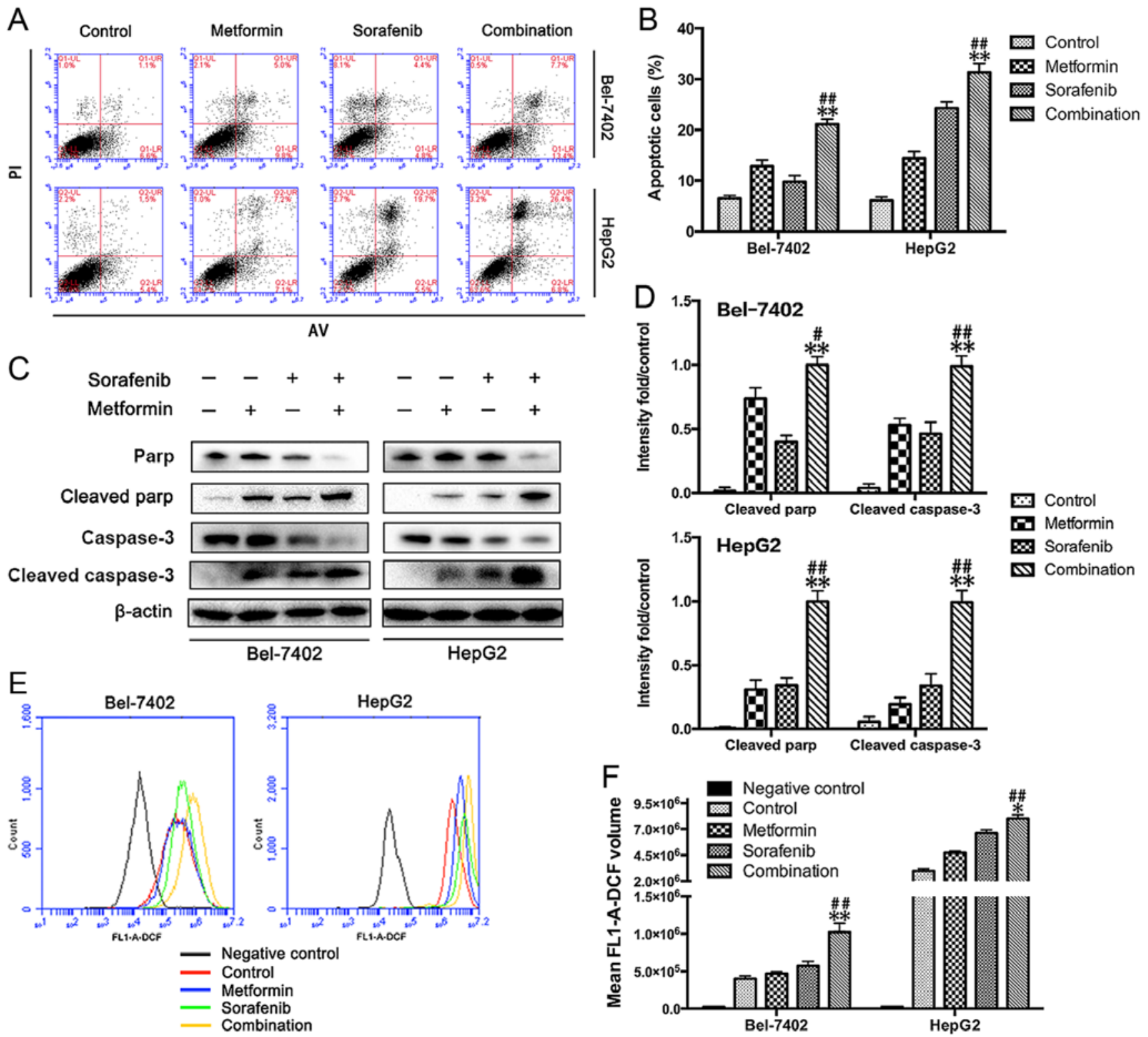

Figure 2. Metformin facilitates the proapoptotic effects of sorafenib on HCC cells through increasing the ROS production induced by sorafenib. (A) After treatment with $10 \mathrm{mmol} / 1$ metformin, $5 \mu \mathrm{mol} / 1$ sorafenib or their combination for $48 \mathrm{~h}$, Bel-7402 cells and HepG2 cells were examined using Annexin V/PI staining and the distribution of apoptotic cells was measured by flow cytometric analysis. (B) The percentages of early apoptosis plus late apoptosis/necrosis are shown in the bar graph. (C and D) Cleaved caspase-3 and cleaved PARP were monitored using western blot analysis. (E) Cells were treated with $10 \mathrm{mmol} / \mathrm{l} \mathrm{metformin}$, $5 \mu \mathrm{mol} / 1$ sorafenib or their combination for $24 \mathrm{~h}$. The intracellular ROS was measured by flow cytometric analysis using an oxidation-sensitive fluorescent probe, DCFH-DA, which can be oxidized to DCF by ROS (the negative control was not treated with DCFH-DA). (F) The mean volumes of DCF are shown in the bar graph as the means \pm SD from 3 independent experiments. Combination vs. metformin ${ }^{\# \#} \mathrm{P}<0.01$; combination vs. sorafenib ${ }^{*} \mathrm{P}<0.05$ and ${ }^{* *} \mathrm{P}<0.01$.

genic assay, but no clones grew (data not shown). Thus, we think the lower cell concentration may increase the sensitivity of HCC cells to metformin and sorafeinib and we decreased the drug concentration in clonogenic assay. So the different drug concentration may be responsible for the different results between CCK- 8 and clonogenic assay. Collectively, these results revealed that a combined treatment of metformin and sorafenib remarkably promotes anti-proliferative effects and G0/G1 cell cycle arrest in HCC cells.

Metformin facilitates sorafenib-induced apoptosis in HCC cells through promoting ROS production. Apoptosis is an underlying antitumor mechanism for both metformin and sorafenib. Here, we investigated the effects of the combined treatment on apoptosis in Bel-7402 and HepG2 cells. The apoptosis assay (Annexin V/PI staining), as shown in Fig. 2A and B, revealed a significant increase in the number of apoptotic cells observed in Bel-7402 and HepG2 cells with a combined treatment of metformin and sorafenib compared to the single drug treatment. To confirm these results, we performed western blot analysis and found increased expression of cleaved PARP and cleaved caspase- 3 in both metformin- and sorafenib-treated Bel-7402 and HepG2 cells. Consistent with the greater apoptotic events, the combined treatment led to higher levels of cleaved PARP and cleaved caspase-3 in both Bel-7402 and HepG2 cells compared to single drug treatment alone (Fig. 2C and D). As sorafenib can induce mitochondrial-dependent ROS production, which 

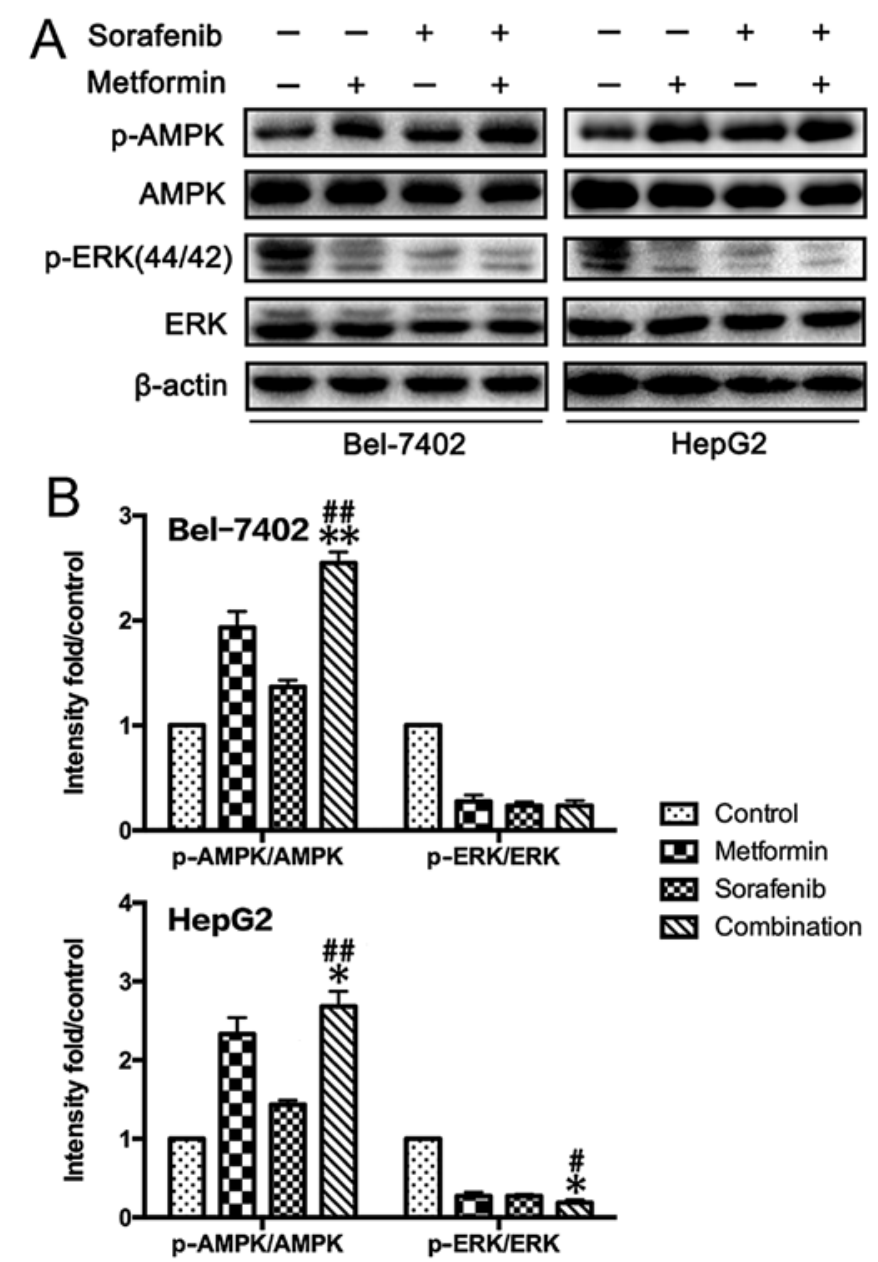

Figure 3. Effects of metformin and sorafenib on the AMPK/ERK pathway in $\mathrm{HCC}$ in vitro. (A and $\mathrm{B}$ ) The effect of metformin and sorafenib single or combined treatment on the activation of AMPK and ERK of HCC cells was determined by western blotting. Combination vs. metformin ${ }^{\#} \mathrm{P}<0.05$ and ${ }^{\# \#} \mathrm{P}<0.01$; combination vs. sorafenib ${ }^{*} \mathrm{P}<0.05$ and ${ }^{* *} \mathrm{P}<0.01$.

elicits cell death in hepatomas (13), we next determined the influence of metformin on sorafenib-induced ROS production. As expected, data in Fig. 2E and F present that metformin $(10 \mathrm{mmol} / \mathrm{l})$ was readily to promote sorafenib $(5 \mu \mathrm{mol} / \mathrm{l})$ induced ROS production.

Metformin and sorafenib regulate the AMPK/ERK and mTORC1/2 pathways. To analyze the potential molecular mechanism, we investigated the effects of metformin and sorafenib on the AMPK/ERK and mTOR pathways in HCC cells (Fig. 3). Both metformin ( $10 \mathrm{mmol} / \mathrm{l})$ and sorafenib $(5 \mu \mathrm{mol} / \mathrm{l})$ activated AMPK and inhibited ERK compared to untreated HCC cells. At concentrations of 0,5 and $10 \mathrm{mmol} / 1$, metformin significantly inhibited the mTORC1 (p-mTOR Ser2448, p-p70S6K Thr389, p-Raptor Ser792, p-4E BP1 Thr37/46) but activated the mTORC2 (p-mTOR Ser2481, p-Rictor Thr1135, p-AKT Ser473) (Fig. 3) pathway. Inconsistent results were obtained after sorafenib treatment, which suppressed the activation of both the mTORC1 and the mTORC2 pathway in HepG2 and Bel-7042 cells (Fig. 4A and B). The consequences of the combination of metformin and sorafenib on mTOR $1 / 2$ networks was further investigated, revealing that sorafenib reversed the activation status of mTORC 2 induced by metformin and enhanced the suppression of mTORC1 by metformin in HCC cells (Fig. 4C and D). This result may explain the additional reduction in proliferation upon combined treatment.

Combined treatment with metformin and sorafenib efficiently reduces HCC growth in a HCC xenograft model. To further validate our in vitro results showing the anti-proliferative effects of combined treatment of metformin and sorafenib, we treated male athymic nude mice bearing palpable tumors $\left(\sim 100 \mathrm{~mm}^{3}\right)$ of Bel-7402 xenografts with control (vehicle-treated mice), metformin (200 mg/kg/day), sorafenib (30 $\mu \mathrm{g} / \mathrm{kg} /$ day) and their combination (Fig. 5A-C) for 28 days. The tumor volumes of the combined treatment group were significantly reduced compared to the groups treated with either metformin or sorafenib. Consistent with the in vitro data, immunohistochemistry and TUNEL analyses (Fig. 5D and E) of the xenograft tumors revealed that the metformin and sorafenib combination effectively inhibited the expression of Ki-67, a marker for representing tumor proliferation. Moreover, metformin facilitated the sorafenib induced apoptosis in xenograft tumors as evaluated by the cleaved caspase- 3 staining and TUNEL assay.

Combined treatment of metformin and sorafenib suppressed active status for ERK and mTOR pathways in HCC xenograft tumors. Immunohistochemistry and western blot analysis of the xenograft tumors revealed that metformin and sorafenib inhibited the activation of ERK in the in vivo xenograft model as well (Fig. 6A-C). Similarly, xenograft tumors were further examined for the status of p-mTOR (Ser2448 and Ser2481) and p-AKT (Ser473) after treatment with the control, metformin, sorafenib and their combination (Fig. 6). Consistent with the in vitro results, sorafenib significantly reversed the activation status of mTORC 2 and the combined treatment of metformin and sorafenib synergistically abrogated activity of mTORC1.

Inhibition of autophagy induced by metformin and sorafenib combined treatment promotes apoptotic death in $\mathrm{HCC}$ cells. Since combined treatment of metformin and sorafenib profoundly inhibit the mTOR pathway, which is known to closely regulate autophagy, the potent influences of both on HCC autophagy was further determined. Transmission electron microscopy (TEM) and western blot analysis were used to monitor the autophagic status in HCC cells and clearly demonstrated that accelerated autophagy occurs after $48 \mathrm{~h}$ treatment with metformin and sorafenib (Fig. 7A and B). The results of TEM revealed increased autophagic vacuoles in HCC cells treated with metformin and sorafenib combination compared to single drug or control. Microtubule-associated protein light chain 3 (LC3) is a specific marker for autophagy initiation. When autophagy occurred, the cytoplasmic form of LC3 (LC3-I) converted to the pre-autophagosomal and autophagosomal membrane-bound form of LC3 (LC3-II) and p62 was degraded (14). However, two autophagy inhibitors CQ and 3MA could both promote apoptotic death induced by metformin and sorafenib in HCC cells (Fig. 7C-E). CQ could prevent fusion of endosomes and lysosomes and inhibit the formation of autophagosomes. Thus, accumulated LC3-II and p62 could be detected by western blot analysis (Fig. 7B and E) The 3MA is a phosphoinositide 3-kinase inhibitor that inhibits 
A

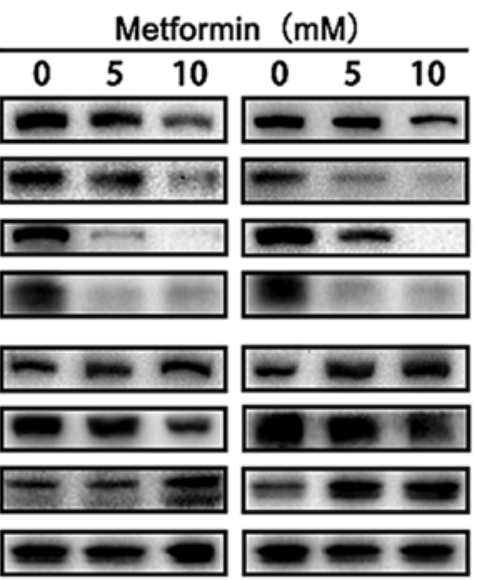

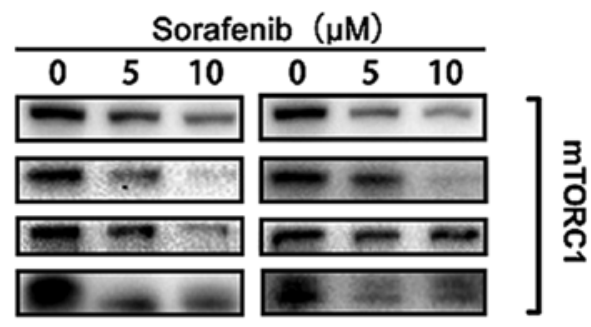
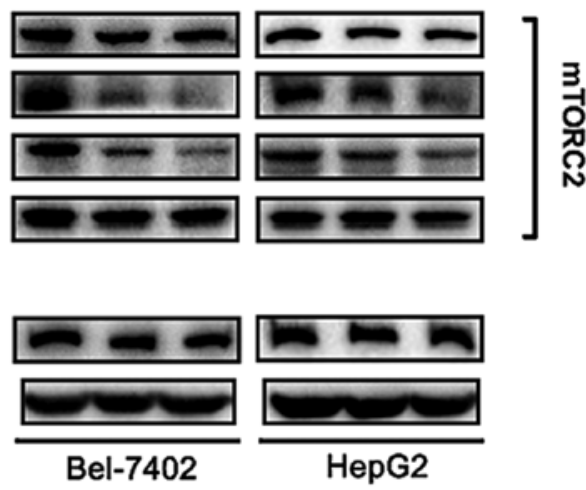

HepG2
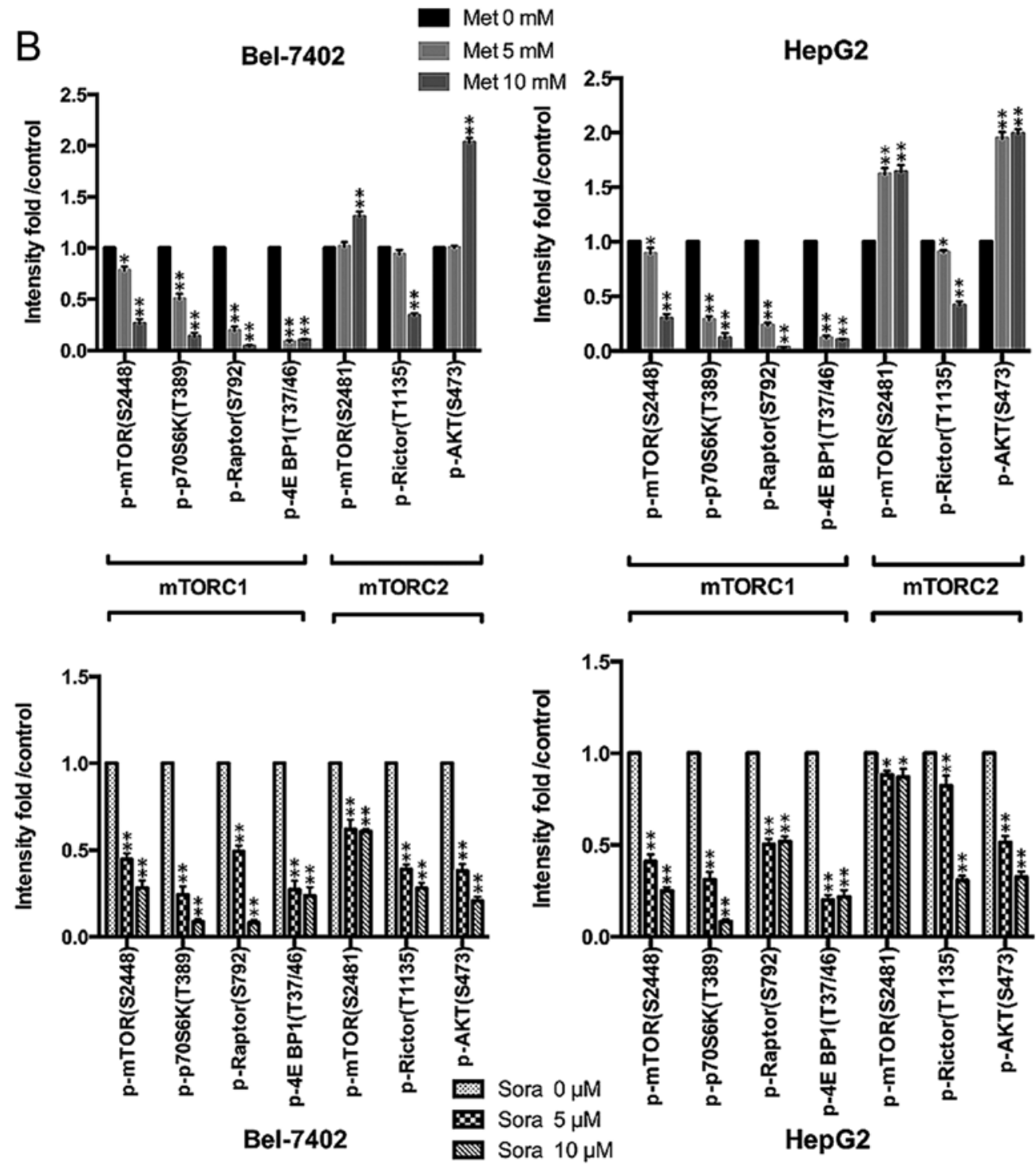

Figure 4. Effects of metformin and sorafenib on the mTOR pathway in HCC in vitro. (A) The activation status of mTORC1 (p-mTOR Ser2448, p-p70S6K Thr389, p-Raptor Ser792, p-4E BP1 Thr37/46) and mTORC2 (p-mTOR Ser2481, p-Rictor Thr1135, p-AKT Ser473) in Bel-7402 cells and HepG2 cells was determined by western blot analysis after the cells were treated with 0,5 or $10 \mathrm{mmol} / 1 \mathrm{metformin}$ or $0,5 \mathrm{or} 10 \mu \mathrm{mol} / 1$ sorafenib for $48 \mathrm{~h}$. (B) The band intensities were quantified using Image Lab 5.0 software and are represented as the means \pm SD from 3 independent experiments. $\left({ }^{*} \mathrm{P}<0.05\right.$ and $\left.{ }^{* * *} \mathrm{P}<0.01\right)$. 

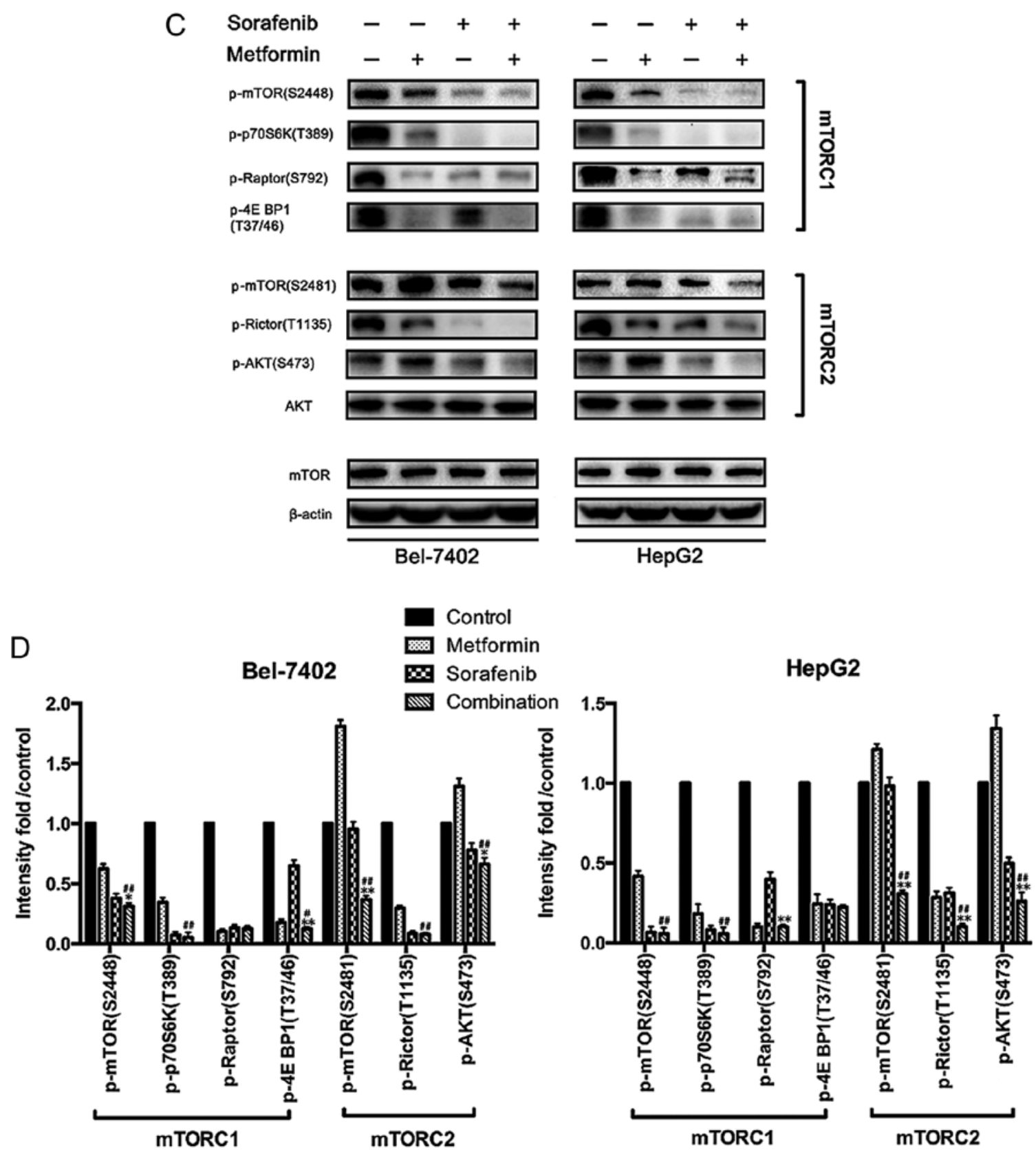

Figure 4. Continued. (C) After Bel-7402 cells and HepG2 cells were treated with $10 \mathrm{mmol} / 1$ metformin, $5 \mu \mathrm{mol} / 1$ sorafenib or their combination, the activation status of mTORC1 and mTORC2 of the cells was determined by western blot analysis. (D) The band intensities were quantified using Image Lab 5.0 software and are represented as the means \pm SD from 3 independent experiments. Combination vs. metformin ${ }^{\#} \mathrm{P}<0.05$ and ${ }^{\# \#} \mathrm{P}<0.01$; combination vs. sorafenib ${ }^{*} \mathrm{P}<0.05$ and ${ }^{* *} \mathrm{P}<0.01$.

autophagy before the formation of autophagosomes. In conclusion, these results revealed that combined treatment of metformin and sorafenib triggered autophagy in HCC cells, which may be cytoprotective as inhibition of autophagy by CQ or 3MA could promote metformin and sorafenib induced apoptotic cell death. Especially, for the LC3-II band intensity in Fig. 7E, we found that when the cells were treated with $\mathrm{CQ}$, LC3-II displayed strong increase compared to the other groups. The band intensity would be overtested in group with CQ if the other groups could be displayed as in Fig. 7B. So, the bands in the other groups were too weak for accurate quantification.

Collectively, we propose a potential molecular mechanism where metformin and sorafenib inhibit HCC development via modulating AMPK and the mTOR1/2 pathway (Fig. 8).

\section{Discussion}

HCC is a complex tumor type with multiple genetic aberrations. Many signaling pathways are activated during HCC initiation and progression. The multi-kinase inhibitor sorafenib is administered to patients with unresectable/non-ablatable or advanced-stage HCC. However, sorafenib only improves median overall survival by $\sim 3$ months $(4,6)$. Thus, single-agent therapy is insufficient for HCC treatment. The multi-targeting-based approach is of particular significance in HCC treatment. In the present study, the combination of sorafenib with metformin, a recently described antitumor agent, was tested for antitumor effects in the HCC cell lines HepG2 and Bel-7402. 

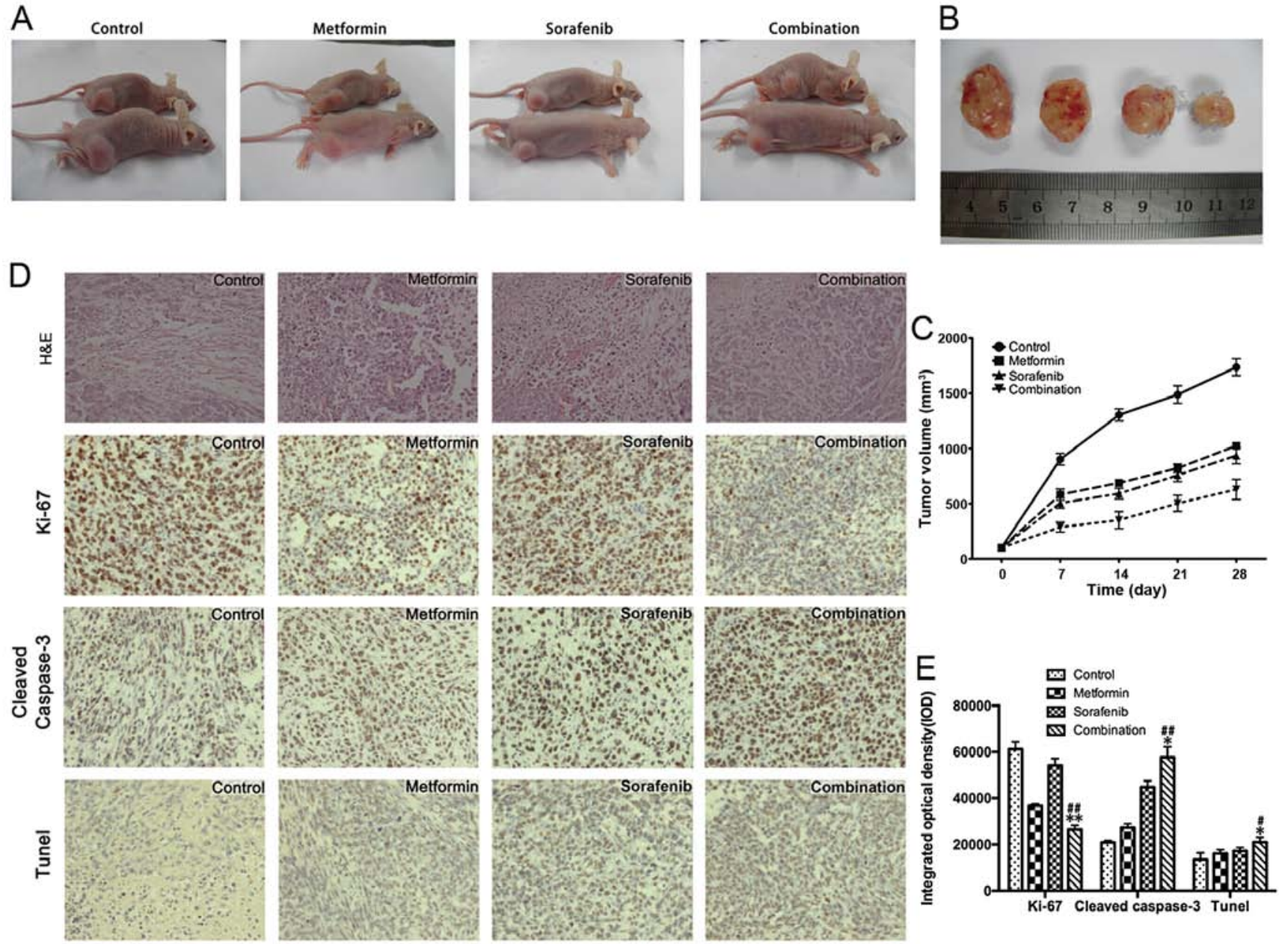

Figure 5. Metformin and sorafenib in combination potentiates the antiproliferative effect of the single drug treatments in vivo. (A) Bel-7402 cells were implanted subcutaneously into the flank regions of nude mice. When the tumor volume reached $\sim 100 \mathrm{~mm}^{3}$, vehicle (control), metformin (200 mg/kg/day, intraperitoneal injection), sorafenib (30 $\mu \mathrm{g} / \mathrm{kg} / \mathrm{day}$, intragastric administration), or their combination were administered for 4 weeks, 5 times/week. (B) At 4 weeks, the mice were euthanized and the tumors are shown. (C) The growth curve shows the 4 weeks of drug treatment. (D) Representative hematoxylin and eosin (H\&E) stained images are shown and the expression of Ki-67 and cleaved caspase-3 in the tumors were detected by IHC. In addition, apoptotic cells in the tumors from mice were detected by the TUNEL assay. (E) The data were quantified and are represented as the means \pm SD from 3 independent experiments. Combination vs. metformin ${ }^{\# \#} \mathrm{P}<0.01$; combination vs. sorafenib ${ }^{*} \mathrm{P}<0.05$ and ${ }^{* *} \mathrm{P}<0.01$.

The HCC proliferation data were identical to those from our previous study in intrahepatic cholangiocarcinoma cells (11), in which metformin plus sorafenib effectively inhibited the proliferation of HCC cells compared to the single-agent treatment as shown by the CCK- 8 assay, cell cycle determination, the colony formation assay and a xenograft model in nude mice. These results are consistent with some recent studies $(15,16)$. Moreover, according to the results of cellular and xenograft apoptosis and activated PARP and caspase-3, metformin effectively facilitates the proapoptotic effects of sorafenib on HCC cells through the promotion of reactive oxygen species (ROS) production induced by sorafenib.

The treatment doses we used in the present study, were consulted from previous reports $(15,16)$. Considering the doses used in the clinical setting, a recent study has reviewed the in vitro and in vivo studies of anticancer research by metformin and concluded that doses of metformin used in mice, which showed anticancer effect, was much less than commonly used in clinical practice (17). For sorafenib, as it is approved by Food and Drug Administration (FDA) for advanced HCC, the concentration we used in mice
(30 $\mu \mathrm{g} / \mathrm{kg} /$ day) was much less than commonly used in HCC patients (400 mg/day) (http://www.accessdata.fda.gov/drugsatfda_docs/label/2013/021923s016lbl.pdf). Thus, the doses we used in the present study were comparable and acceptable in cancer related studies.

Additional signaling analysis suggested that the underlying molecular mechanism was associated with the MAPK and mTOR pathways. We discovered that metformin as well as sorafenib would greatly suppress ERK1/2 activation, and a stronger effect was observed for the combined treatment. Metformin-mediated HCC growth arrest is associated with the AMPK and mTORC1 pathways. Indeed, the activation of AMPK, a well-known metformin effector, suppresses ERK1/2 activation (18-20) and shuts down cell cycle progression. We observed that metformin activated AMPK, which would in turn suppress ERK1/2 activation. The sorafenib-induced reduction in ERK1/2 phosphorylation could be directly explained by the universal inhibitory effects of a multi-kinase acting on ERK1/2. However, it is quite interesting that we also observed sorafenib having similar effects to metformin in regulating mTORC1 activity, as well as AMPK activation, indicating that 

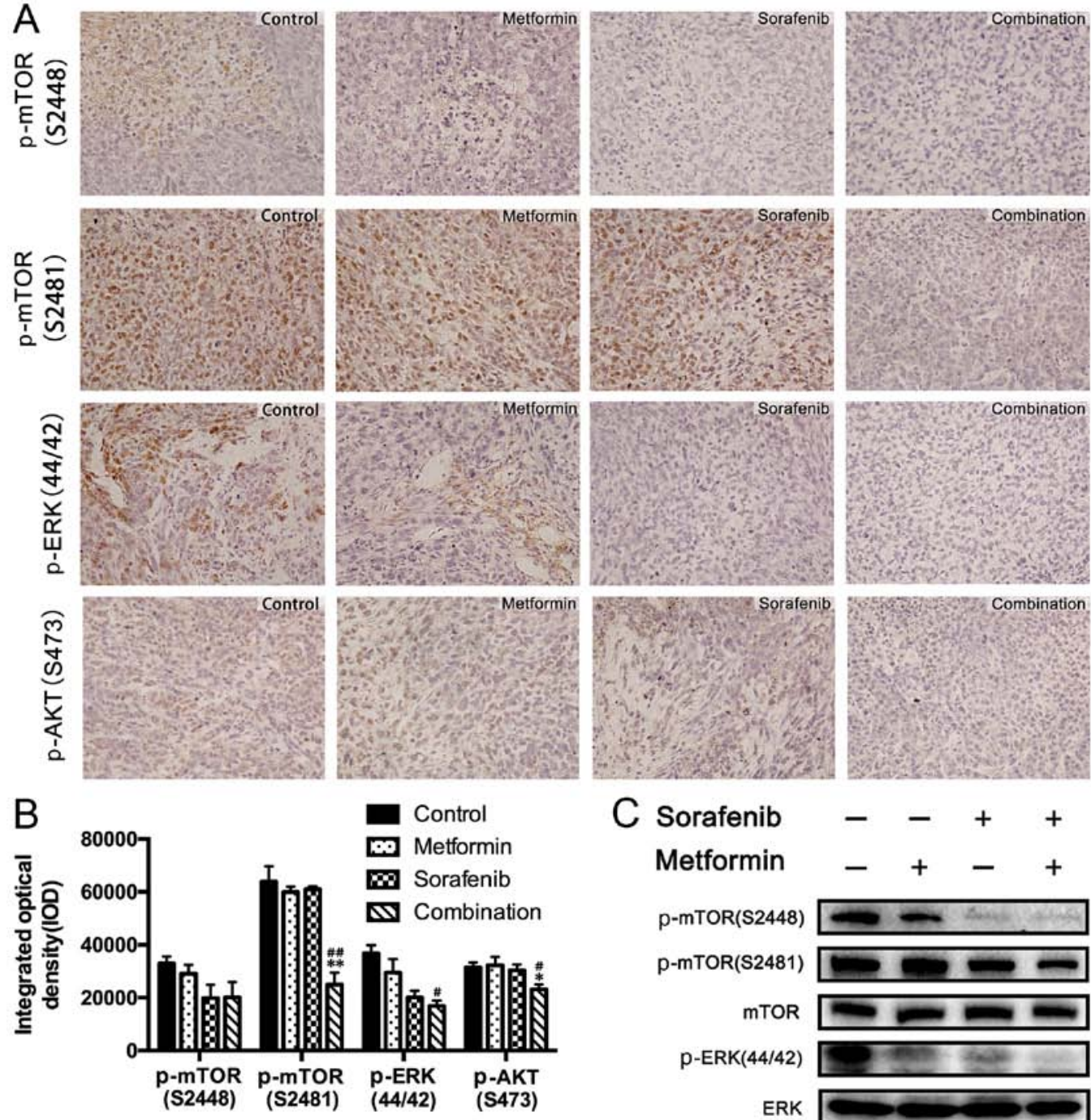

mTOR
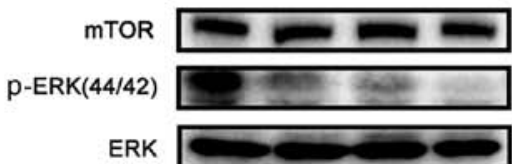

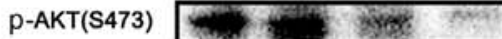
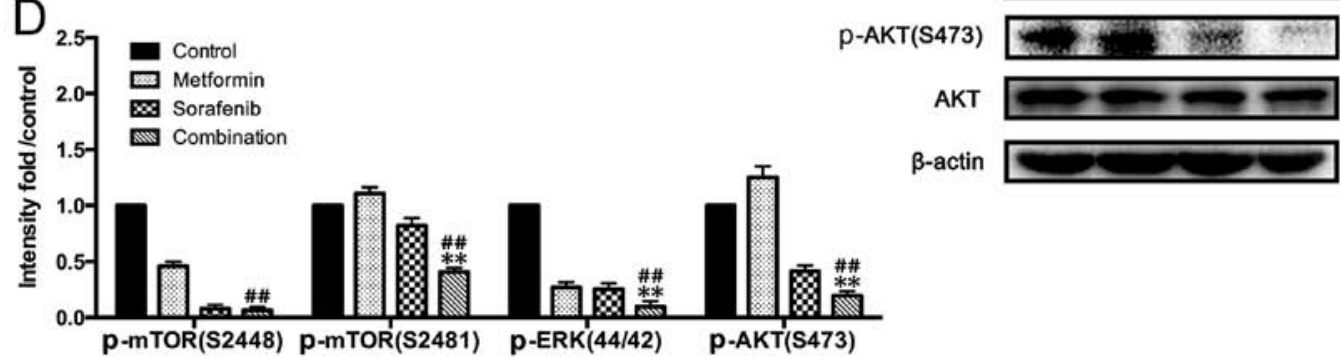

Figure 6. Effect of metformin and sorafenib combination on the mTOR pathway in HCC in vivo. (A and C) The activation status of p-mTOR Ser2448, p-mTOR Ser2481, p-AKT Ser473 and p-ERK (44/42) of the tumors from mice were detected by IHC and western blotting. (B) The data were quantified and are represented as the means \pm SD from 3 independent experiments. (D) The band intensities were quantified using Image Lab 5.0 software and are presented as the means \pm SD from 3 independent experiments. Combination vs. metformin ${ }^{\#} \mathrm{P}<0.05$ and ${ }^{\# \#} \mathrm{P}<0.01$; combination vs. sorafenib ${ }^{*} \mathrm{P}<0.05$ and ${ }^{* *} \mathrm{P}<0.01$.

sorafenib may have other mechanisms of controlling ERK activation. Although the molecular mechanisms of metformin and sorafenib in controlling HCC growth are complex or interactive, the combination of both would further enhance AMPK activation and inhibit the active status of mTORC1 and ERK1/2, with a more profound HCC growth suppression effect than any single treatment.

The serine/threonine kinase mTOR forms two multi-protein complexes, mTOR complex 1 (mTORC1) and mTORC2 (21). mTORC1 consists of proteins such as the regulatory-associated protein of mTOR (Raptor) and the mammalian lethal with SEC13 protein 8 (mLST8), and regulates cell growth and proliferation through modifying its substrates eIF4E-binding protein 1 (4E-BP1) and p70 ribosomal subunit S6 kinase (p70S6k) (21). p70S6k phosphorylates rapamycin-insensitive companion of mTOR (Rictor), the core component of the mTORC2 complex, and negatively regulates mTORC2 (22). Conversely, mTORC 2 regulates mTORC1 by activating AKT as part of a negative feedback mechanism $(22,23)$. Thus, there is a negative feedback loop mechanism between mTORC1/mTORC 2 . The feedback between mTORC 1 and mTORC 2 and cross-talk between the PI3K/AKT/mTOR pathway and the Ras/Raf/MAPK pathway may be partly responsible for the resistance or failure of single-agent administration $(24,25)$. We asked whether the 

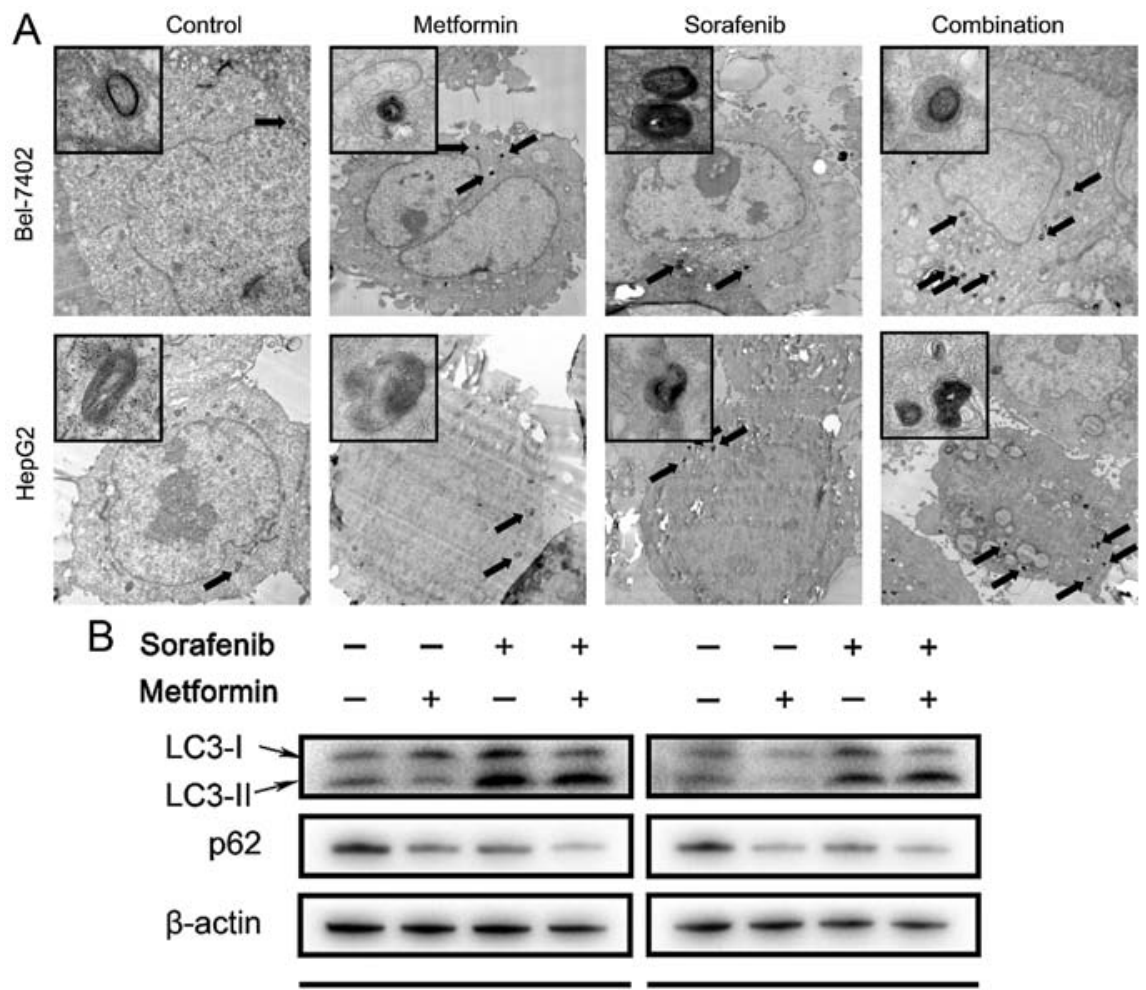

Bel-7402

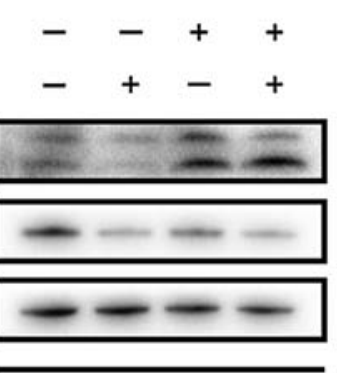

HepG2

C

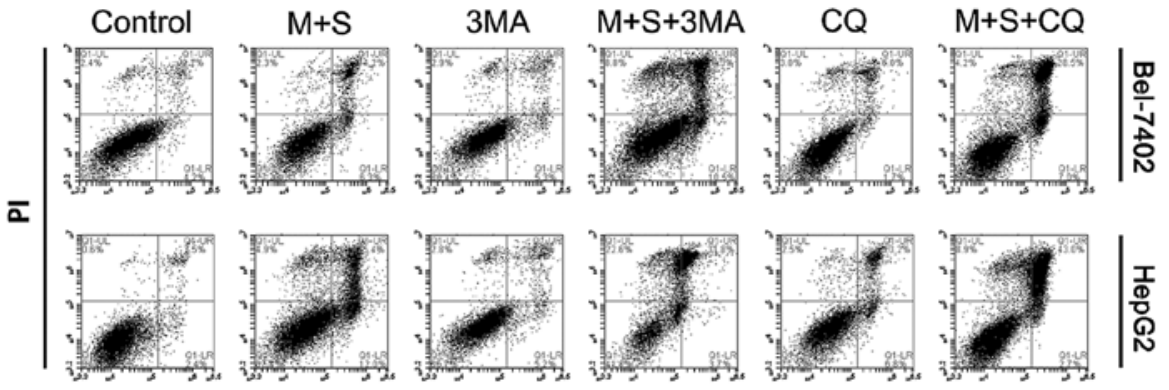

AV

D

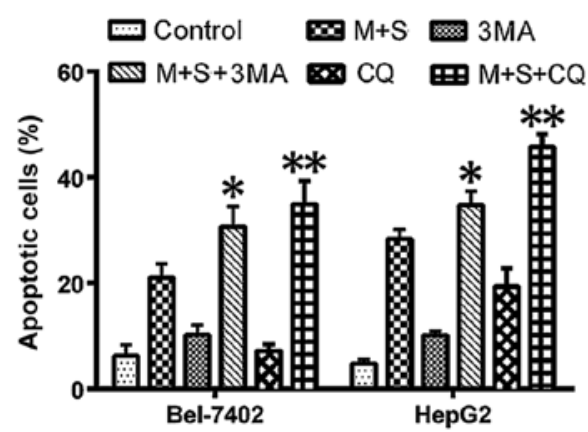

E

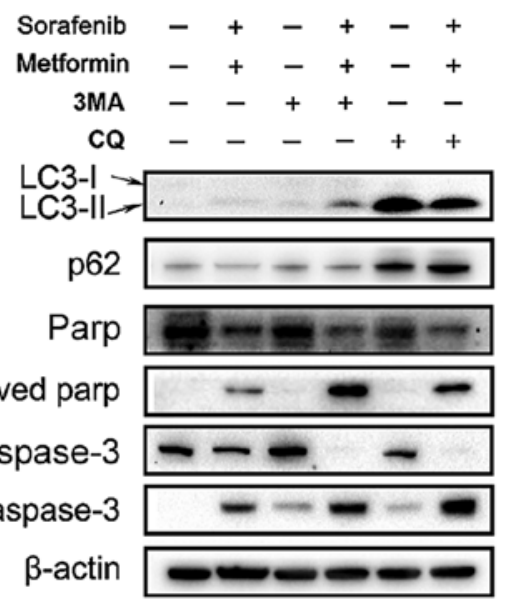

Bel-7402
$-+-++$

$-+-+-+$

$-+++-$

$-\quad--++$
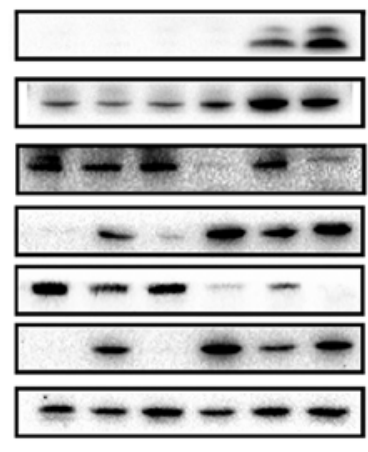

HepG2

Figure 7. Inhibition of autophagy by 3MA or CQ sensitizes HCC cells to metformin-induced apoptotic cell death. (A) Transmission electron microscopy (TEM) images showed autophagic vacuoles (arrows) observed in metformin $(10 \mathrm{mmol} / \mathrm{l})$ and sorafenib $(5 \mu \mathrm{mol} / \mathrm{l})$ single or combination-treated Bel-7402 and HepG2 cells for $48 \mathrm{~h}$. (B) Two main autophagy-related proteins LC3-I/II and p62 were detected using western blot analysis in metformin (10 mmol/l) and sorafenib (5 $\mu \mathrm{mol} / \mathrm{l})$ single or combination-treated Bel-7402 and HepG2 cells for $48 \mathrm{~h}$. (C) Two autophagy inhibitors chloroquine (CQ, $10 \mu \mathrm{mol} / \mathrm{l}$ ) and 3-methyladenine (3MA, $5 \mathrm{mmol} / \mathrm{l})$ were used to abrogate the autophagy induced by metformin and sorafenib combination for $48 \mathrm{~h}$. Then, apoptotic cells were detected by Annexin V/PI staining and flow cytometric analysis. (D) The percentages of early apoptosis plus late apoptosis/necrosis are shown in the bar graph. (E) Cleaved caspase-3, cleaved PARP, LC3-I/II and p62 were monitored using western blot analysis. Metformin+sorafenib+CQ/3MA vs. metformin+sorafenib ${ }^{*} \mathrm{P}<0.05$ and ${ }^{* *} \mathrm{P}<0.01$. 


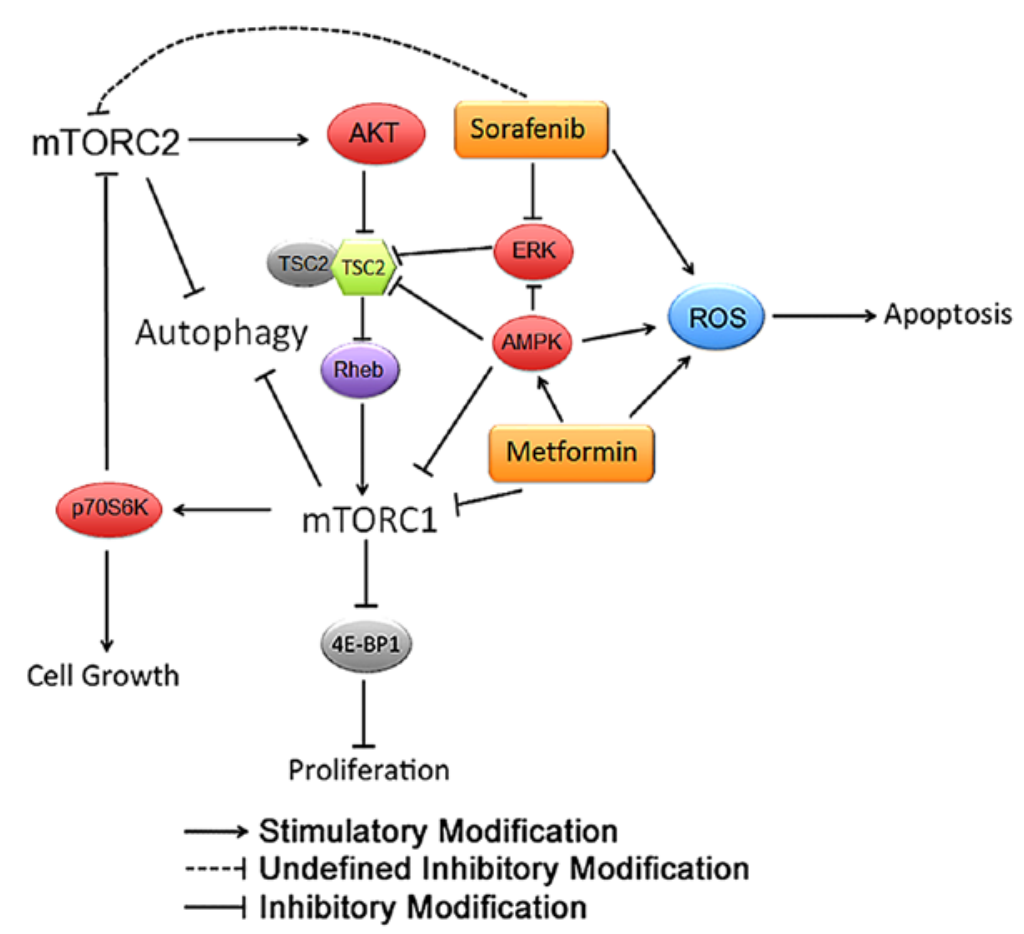

Figure 8. Proposed mechanisms responding to metformin- and sorafenib-induced effects in HCC. Metformin effectively facilitates the proapoptotic effects of sorafenib on HCC cells through the promotion of reactive oxygen species (ROS) production induced by sorafenib. For the regulation of mTOR pathway, metformin activated mTOC2/AKT via a negative feedback loop of AMPK/mTORC1/mTORC2 pathway. With an undefined mechanism, sorafenib effectively reverses the activation status of mTORC2 and further enhances the suppression of mTORC1 induced by metformin. Metformin and sorafenib may cooperate to promote autophagy in HCC cells by regulation of mTOR pathway.

anti-proliferative properties of a combined treatment with metformin and sorafenib are dependent on disruption of the mTORC1 and mTORC2, inhibition of the PI3K/AKT/mTOR pathway or the Ras/Raf/MAPK pathway. Consistent with a recent study (26), we found that metformin may activate mTORC2/AKT through the mTORC1/mTORC2 feedback loop. We further observed that sorafenib amplifies suppression effect of metformin on HCC both in vitro and in vivo. Sorafenib abrogates the activation of mTORC2/AKT induced by metformin while synergistically inactivating $\mathrm{MTORC} 1$ with metformin, which may partly account for the potential mechanisms. Interestingly, a single sorafenib treatment inhibits both mTORC1 and mTORC2 signaling, which is contradictory to results in other HCC cell lines (27) or other malignancies (28). This contradiction implies that the effects of sorafenib in cancer may be cell line- and tissue-specific. It will be valuable to explore the molecular explanation of the discrepant effects on mTORC2 of sorafenib in our further studies.

However, a recent clinical study found that the concomitant use of sorafenib and metformin was associated with a poorer prognosis compared to sorafenib alone in patients with advanced HCC (29). In this study, the authors speculated that chronic treatment of metformin may impel HCC cells to intrinsic resistance to metformin, and also to sorafenib. Thus, in the present study, we further evaluated the autophagic status of HCC cells treated with metformin and sorafanib, as autophagy always mediates the drug-resistant effect of tumor cells. The mTOR pathway, a promising regulator for autophagy (30), may effectively regulate the potential cell death mechanism and chemotherapy response (31). Autophagy is able to either inhibit or promote cancer cell growth in different cellular contexts (32). Combined treatment of metformin and sorafenib triggered higher levels of autophagy compared to single or no drug treatment in HCC cells. Pharmacological inhibition of autophagy sensitized HCC cells to metformin and sorefenib-induced apoptotic cell death, which implies that metformin and sorafenib-mediated autophagy is an anti-apoptotic death mechanism rather than a cell death mechanism. Mechanically, the anti-autophagy treatment should be considered in metformin and sorafenib as well as mTOR inhibitor-based treatments in HCC cells. Moreover, a recent basic study described that metformin promoted anti-metastasis effect of sorafenib in HCC (33), which supported the combination treatment of metformin and sorafenib in HCC. A phase II study recruiting patients with advanced HCC for combined treatment with sorafenib and metformin is proceeding (ClinicalTrials.gov identifier: NCT02672488), which may help clear the value of metformin and sorafenib combination treatment in advanced HCC patients.

Some shortages of the present study should be discussed. Agents with different concentrations may exert different biological effects, and a combination use of the two agents with different concentrations needs to be conducted in future studies to validate the molecular mechanism by treatment of metformin and sorafenib in HCC. In addition, the function of mTORC2 is less studied and mTORC 2 may play significant role in cell migration and energy metabolism. How sorafenib inactivates the mTORC2 should be further explored.

In conclusion, our results proved that the combination of metformin and sorafenib promotes apoptosis and inhibits the proliferation of HCC in vitro and in vivo. Activation of mTORC2 provides an escape mechanism for the HCC cells from metformin treatment. Sorafenib effectively reverses 
the activation status of mTORC2 induced by metformin and further enhances the suppression of mTORC1 by metformin in $\mathrm{HCC}$ in vitro and in vivo. Metformin and sorafenib cooperate to promote apoptosis and autophagy in HCC cells. Inhibition of autophagy profoundly enhances the apoptosis of HCC cells induced by metformin and sorafenib. The anti-autophagy treatment should be considered in metformin and sorafenib based treatments in HCC cells. These results may help to ameliorate the strategies of metformin- or sorafenib-based chemotherapeutic treatment of patients with $\mathrm{HCC}$ in the clinical setting.

\section{Acknowledgements}

This study was supported by grants from the National Natural Science Foundation of China (no. 81372328) and the Medical and Health Science and Technology Program of Zhejiang province (nos. 2015K YB062 and 201352853).

\section{References}

1. Siegel R, Ma J, Zou Z and Jemal A: Cancer statistics, 2014. CA Cancer J Clin 64: 9-29, 2014.

2. Jemal A, Bray F, Center MM, Ferlay J, Ward E and Forman D: Global cancer statistics. CA Cancer J Clin 61: 69-90, 2011.

3. Perz JF, Armstrong GL, Farrington LA, Hutin YJ and Bell BP: The contributions of hepatitis $B$ virus and hepatitis $C$ virus infections to cirrhosis and primary liver cancer worldwide. J Hepatol 45: 529-538, 2006.

4. Llovet JM, Ricci S, Mazzaferro V, Hilgard P, Gane E, Blanc JF de Oliveira AC, Santoro A, Raoul JL, Forner A, et al; SHARP Investigators Study Group: Sorafenib in advanced hepatocellular carcinoma. N Engl J Med 359: 378-390, 2008.

5. Wilhelm SM, Adnane L, Newell P, Villanueva A, Llovet JM and Lynch M: Preclinical overview of sorafenib, a multikinase inhibitor that targets both Raf and VEGF and PDGF receptor tyrosine kinase signaling. Mol Cancer Ther 7: 3129-3140, 2008.

6. Cheng AL, Kang YK, Chen Z, Tsao CJ, Qin S, Kim JS, Luo R, Feng J, Ye S, Yang TS, et al: Efficacy and safety of sorafenib in patients in the Asia-Pacific region with advanced hepatocellular carcinoma: A phase III randomised, double-blind, placebocontrolled trial. Lancet Oncol 10: 25-34, 2009.

7. Lee MS, Hsu CC, Wahlqvist ML, Tsai HN, Chang YH and Huang YC: Type 2 diabetes increases and metformin reduces total, colorectal, liver and pancreatic cancer incidences in Taiwanese: A representative population prospective cohort study of 800,000 individuals. BMC Cancer 11: 20, 2011

8. Chaiteerakij R, Yang JD, Harmsen WS, Slettedahl SW, Mettler TA, Fredericksen ZS, Kim WR, Gores GJ, Roberts RO, Olson JE, et al: Risk factors for intrahepatic cholangiocarcinoma: Association between metformin use and reduced cancer risk. Hepatology 57: 648-655, 2013.

9. Jalving M, Gietema JA, Lefrandt JD, de Jong S, Reyners AK, Gans RO and de Vries EG: Metformin: Taking away the candy for cancer? Eur J Cancer 46: 2369-2380, 2010.

10. Donadon V,Balbi M, Mas MD, Casarin P and Zanette G: Metformin and reduced risk of hepatocellular carcinoma in diabetic patients with chronic liver disease. Liver Int 30: 750-758, 2010.

11. Ling S, Feng T, Ke Q, Fan N, Li L, Li Z, Dong C, Wang C, $\mathrm{Xu}$ F, Li Y, et al: Metformin inhibits proliferation and enhances chemosensitivity of intrahepatic cholangiocarcinoma cell lines. Oncol Rep 31: 2611-2618, 2014.

12. Ling S, Tian Y, Zhang H, Jia K, Feng T, Sun D, Gao Z, Xu F, Hou Z, Li Y, et al: Metformin reverses multidrug resistance in human hepatocellular carcinoma Bel 7402/5 fluorouracil cells. Mol Med Rep 10: 2891-2897, 2014.

13. Chiou JF, Tai CJ, Wang YH, Liu TZ, Jen YM and Shiau CY: Sorafenib induces preferential apoptotic killing of a drug- and radio-resistant Hep G2 cells through a mitochondria-dependent oxidative stress mechanism. Cancer Biol Ther 8: 1904-1913,2009.

14. Klionsky DJ, Abdelmohsen K, Abe A, Abedin MJ, Abeliovich H, Acevedo Arozena A, Adachi H, Adams CM, Adams PD, Adeli K, et al: Guidelines for the use and interpretation of assays for monitoring autophagy (3rd edition). Autophagy 12: 1-222, 2016.
15. Saito T, Chiba T, Yuki K,Zen Y, Oshima M, Koide S, Motoyama T, Ogasawara S, Suzuki E, Ooka Y, et al: Metformin, a diabetes drug, eliminates tumor-initiating hepatocellular carcinoma cells. PLoS One 8: e70010, 2013.

16. Guo Z, Cao M, You A, Gao J, Zhou H, Li H, Cui Y, Fang F, Zhang W, Song T, et al: Metformin inhibits the pro-metastatic effect of Sorafenib in hepatocellular carcinoma by upregulating the expression of TIP30. Cancer Sci 107: 507-513, 2016.

17. Anisimov VN: Metformin for cancer and aging prevention: Is it a time to make the long story short? Oncotarget 6: 39398-39407, 2015.

18. Kim JG, Lee SJ, Chae YS, Kang BW, Lee YJ, Oh SY, Kim MC, Kim KH and Kim SJ: Association between phosphorylated AMP-activated protein kinase and MAPK3/1 expression and prognosis for patients with gastric cancer. Oncology 85: 78-85, 2013.

19. Martin M and Marais R: Braking BRAF: AMPK leaves ERK stranded in the desert. Mol Cell 52: 155-156, 2013.

20. Baba Y, Nosho K, Shima K, Meyerhardt JA, Chan AT, Engelman JA, Cantley LC, Loda M, Giovannucci E, Fuchs CS, et al: Prognostic significance of AMP-activated protein kinase expression and modifying effect of MAPK3/1 in colorectal cancer. Br J Cancer 103: 1025-1033, 2010.

21. Bhat M, Sonenberg N and Gores GJ: The mTOR pathway in hepatic malignancies. Hepatology 58: 810-818, 2013.

22. Dibble CC, Asara JM and Manning BD: Characterization of Rictor phosphorylation sites reveals direct regulation of mTOR complex 2 by S6K1. Mol Cell Biol 29: 5657-5670, 2009.

23. Liu P, Gan W, Inuzuka H, Lazorchak AS, Gao D, Arojo O, Liu D, Wan L, Zhai B, Yu Y, et al: Sin1 phosphorylation impairs mTORC2 complex integrity and inhibits downstream Akt signalling to suppress tumorigenesis. Nat Cell Biol 15: 1340-1350, 2013 .

24. Li QL, Gu FM, Wang Z, Jiang JH, Yao LQ, Tan CJ, Huang XY, Ke AW, Dai Z, Fan J, et al: Activation of PI3K/AKT and MAPK pathway through a PDGFR $\beta$-dependent feedback loop is involved in rapamycin resistance in hepatocellular carcinoma. PLoS One 7: e33379, 2012.

25. Wang C, Cigliano A, Delogu S, Armbruster J, Dombrowski F, Evert M, Chen X and Calvisi DF: Functional crosstalk between $\mathrm{AKT} / \mathrm{mTOR}$ and Ras/MAPK pathways in hepatocarcinogenesis: Implications for the treatment of human liver cancer. Cell Cycle 12: 1999-2010, 2013.

26. Yang H, Peng YF, Ni HM, Li Y, Shi YH, Ding WX and Fan J: Basal autophagy and feedback activation of Akt are associated with resistance to metformin-induced inhibition of hepatic tumor cell growth. PLoS One 10: e0130953, 2015.

27. Gedaly R, Angulo P, Hundley J, Daily MF, Chen C, Koch A and Evers BM: PI-103 and sorafenib inhibit hepatocellular carcinoma cell proliferation by blocking Ras/Raf/MAPK and PI3K/AKT/mTOR pathways. Anticancer Res 30: 4951-4958, 2010.

28. Pignochino Y, Dell'Aglio C, Basiricò M, Capozzi F, Soster M, Marchiò S, Bruno S, Gammaitoni L, Sangiolo D, Torchiaro E, et al: The combination of sorafenib and everolimus abrogates mTORC1 and mTORC2 upregulation in osteosarcoma preclinical models. Clin Cancer Res 19: 2117-2131, 2013.

29. Casadei Gardini A, Marisi G, Scarpi E, Scartozzi M, Faloppi L, Silvestris N, Masi G, Vivaldi C, Brunetti O, Tamberi S, et al: Effects of metformin on clinical outcome in diabetic patients with advanced HCC receiving sorafenib. Expert Opin Pharmacother 16: 2719-2725, 2015.

30. Nicoletti F, Fagone P, Meroni P, McCubrey J and Bendtzen K: mTOR as a multifunctional therapeutic target in HIV infection. Drug Discov Today 16: 715-721, 2011.

31. Jung CH, Ro SH, Cao J, Otto NM and Kim DH: mTOR regulation of autophagy. FEBS Lett 584: 1287-1295, 2010.

32. Sun K, Guo XL, Zhao QD, Jing YY, Kou XR, Xie XQ, Zhou Y, Cai N, Gao L, Zhao X, et al: Paradoxical role of autophagy in the dysplastic and tumor-forming stages of hepatocarcinoma development in rats. Cell Death Dis 4: e501, 2013.

33. You A, Cao M, Guo Z, Zuo B, Gao J, Zhou H, Li H, Cui Y, Fang F, Zhang W, et al: Metformin sensitizes sorafenib to inhibit postoperative recurrence and metastasis of hepatocellular carcinoma in orthotopic mouse models. J Hematol Oncol 9: 20, 2016. 